\title{
Enhanced glycosyl hydrolase production in Aspergillus nidulans using transcription factor engineering approaches
}

\author{
Juan Antonio Tamayo-Ramos ${ }^{1,2}$ and Margarita Orejas ${ }^{1 *}$
}

\begin{abstract}
Background: Engineered fungi are attractive platforms for the production of plant cell wall hydrolytic enzymes which, among other biotechnological applications, are required for the efficient conversion of biomass to glucose and other fermentable sugars. As a fungal model system, Aspergillus nidulans provides genetic tools that are of relevance in this context and potentially applicable to industrially important filamentous fungi. The goal of this study is to assess the utility of $A$. nidulans as a host for recombinant protein production.
\end{abstract}

Results: We have successfully applied a transcription factor engineering approach to improve the efficiency of the A. nidulans xylanolytic XInR-x/n $n_{p}$ expression system. Specifically, endo-1,4- $\beta$-xylanases and an a-L-rhamnosidase were chosen as representatives of endogenous and heterologous glycosyl hydrolases involved in plant cell wall deconstruction. By deregulating the expression of the xylanolytic transcriptional activator XInR and modulating the activity of the $\mathrm{pH}$ regulator PacC we improved protein production and reduced production times. Xylanase activity was about 200-fold greater in $g p d A_{p}:: x / n R$ strains compared to controls 4 hours after transfer to inducing conditions, and 10-fold greater after 24 hours. Remarkably, 75\% of the xylanase activity was present in the engineered strains within 4 hours. Engineering XInR expression also had a considerable impact on foreign protein production, especially when the promoter of the 'acidic' $x \ln B$ gene was used to express the transgene. a-L-rhamnosidase activity in $x \ln B_{p}:: r h a A, g p d A_{p}: x \ln R$ strains was about 19-fold greater than that of controls 72 hours after transfer to xylan (about $85 \%$ of the total activity produced), and 10-fold greater at later times (120 hours). The performance of these strains was further enhanced by impeding the proteolytic activation of $\mathrm{PacC}$; introduction of the palA1 allele in $x \ln B_{p}:$ :rhaA, $g p d A_{p}: x / n R$ strains resulted in an additional 2.7-fold increase in a-L-rhamnosidase activity by 48 hours (about $87 \%$ of the total activity produced) and a 1.7-fold increase at later times.

Conclusions: Our results show that the $X \ln R-x / n_{p}$ expression system is a valuable tool for manipulating the production of plant cell wall degrading enzymes in A. nidulans and establish the biotechnological potential of the transcription factors $\mathrm{XInR}$ and PacC to boost and control the strength of xylanolytic promoters.

Keywords: Fungal cell factories, Aspergillus nidulans, Plant cell wall degrading enzymes, Endo-1,4- $\beta$-Xylanase, a-Lrhamnosidase, Protein production, XInR-x/np expression system, Xylan/xylose regulator (XInR), PalA/PacC, Ambient pH regulation

\footnotetext{
* Correspondence: morejas@iata.csic.es

${ }^{1}$ Instituto de Agroquímica y Tecnología de Alimentos, Consejo Superior de Investigaciones Científicas (IATA-CSIC), Agustín Escardino 7, 46980 Paterna, Valencia, Spain

Full list of author information is available at the end of the article
}

\section{Biomed Central}

(C) 2014 Tamayo-Ramos and Orejas; licensee BioMed Central Ltd. This is an Open Access article distributed under the terms of the Creative Commons Attribution License (http://creativecommons.org/licenses/by/2.0), which permits unrestricted use, distribution, and reproduction in any medium, provided the original work is properly credited. The Creative Commons Public Domain Dedication waiver (http://creativecommons.org/publicdomain/zero/1.0/) applies to the data made available in this article, unless otherwise stated. 


\section{Background}

Lignocellulosic biomass is the most abundant source of carbon and energy on Earth and constitutes a clean alternative to fossil fuels [1]. Its specific composition varies between plant species but mainly consists of polysaccharides (predominantly cellulose and hemicellulose) and lignin [2]. A central challenge in the utilization of this material is its enzymatic conversion into fermentable sugars [3,4]. In this context, saprophytic and phytopathogenic fungi are known to coordinately produce, or to have the capacity to produce, a wide spectrum of lignocellulosic enzymes that can synergistically degrade structural polysaccharides in plant cell walls [5-11]. Filamentous fungi are also attractive expression hosts for recombinant protein production, especially due to their high enzyme secretory capacity [12-14]. Whereas the majority of recombinant proteins manufactured by biotechnological industries are produced using a limited number of fungal species, mainly Aspergillus niger, Aspergillus oryzae and Trichoderma reesei, on occasions these fungi may not be appropriate hosts, especially where they are covered by patents and intellectual property rights [12]. Engineering other fungal species suitable for high level production of endogenous or heterologous plant cell wall polysaccharide degrading enzymes will therefore provide an alternative to the hosts traditionally used for commercial exploitation.

Although more widely used in basic research, Aspergillus nidulans, unlike $A$. niger, $A$. oryzae and $T$. reesei, offers the advantages of a well-characterized sexual cycle and thus a tractable genetic system which, along with the availability of many mutant alleles of wide domain and pathwayspecific regulators, provides a major advantage for strain construction and development. Analysis of its genome [15] in combination with proteomic studies $[9,16]$ show it to have a similar polysaccharide degradation potential to that of the industrial fungi, and in addition the regulatory mechanisms involved in controlling the expression of plant cell wall degrading activities are mostly conserved between it and industrially important fungi [17-20]. Finally, the use of $A$. nidulans as a production vehicle could provoke less concern regarding mycotoxin synthesis since its genome encodes the metabolic pathway for the less toxic compound sterigmatocystin compared to certain industrial strains which still retain the capacity to produce very harmful mycotoxins [21,22].

An important factor for the production of recombinant proteins concerns the efficiency of transcription of the encoding genes. In this regard a variety of promoters are available in $A$. nidulans and the usefulness of some of them beyond the fungal kingdom has been demonstrated $[23,24]$. Both constitutive (such as that of the gpdA gene which encodes glyceraldehyde- 3 phosphate dehydrogenase) and inducible (for example that of the alcA gene which encodes alcohol dehydrogenase I) promoters are utilized in
A. nidulans to drive gene expression, though regulated promoters are frequently preferred when the product is toxic or compromises growth. An ideal inducible promoter for industrial processes should be inexpensive to activate and capable of achieving high levels of expression after induction. In this context, we are exploring the potential of other regulated $A$. nidulans promoters, such as those of the xylanolytic genes $x \ln A$ (encodes xylanase $\mathrm{X}_{22}$ ) and $x \ln B$ (encodes xylanase $\mathrm{X}_{24}$ ), with the aim of obtaining improvements in expression levels and/or production times of both endogenous and heterologous high-value plant cell wall degrading enzymes. The biotic and abiotic factors influencing the expression of these promoters $\left(x \ln A_{\mathrm{p}}\right.$ and $\left.x \ln B_{\mathrm{p}}\right)$ and the transcriptional repressors and activators associated with them have been thoroughly characterized [18,25-27]. An additional advantage of these alternative promoters is the almost complete lack of basal level of expression in the absence of the inducer. In this regard, the utility of the $A$. nidulans $x \ln A$ gene promoter has been previously demonstrated for the conditional expression of the Cre/loxP system [28]. The question now is how our current knowledge of the molecular mechanisms regulating the $\mathrm{X} \ln \mathrm{R}-x \ln _{\mathrm{p}}$ expression system can be best employed to further improve productivity.

The activities of the $x \ln A$ and $x \ln B$ promoters are tightly regulated by at least three mechanisms: ambient $\mathrm{pH}$ regulation mediated by the wide-domain transcriptional factor $\mathrm{PacC}$, carbon catabolite repression (CCR) mediated by the wide-domain repressor CreA and specific induction in the presence of xylan or xylose controlled by the $\mathrm{Zn}(\mathrm{II})_{2} \mathrm{Cys}_{6}$ protein $\mathrm{X} \ln \mathrm{R}$, which is itself transcriptionally regulated by CreA [18,25-27]. For efficient induction, $x \ln A_{\mathrm{p}}$ requires both xylose and alkaline $\mathrm{pH}$ whereas $x \ln B_{\mathrm{p}}$ requires xylose and acidic $\mathrm{pH}$ [25]. Previous studies that have demonstrated the roles of PacC, CreA and XlnR in the regulation of the $A$. nidulans xylanolytic system led to the identification of genetic backgrounds in which the expression of $x \ln A$ or $x \ln B$ was strongly enhanced compared to controls [18,25-27]. Notable examples are $c r e A^{d} 30$ and $g p d A_{\mathrm{p}}:: x \ln R$ $\left(x \ln A\right.$ and $x \ln B$ overexpressed), pac $C^{c} 14(x \ln A$ overexpressed) and palA1 ( $x \ln B$ overexpressed because the proteolytic activation of $\mathrm{PacC}$ is impaired) mutant strains. Thus, manipulation of the expression or activity of the regulators CreA, XlnR or PacC (either alone or in combination) could be exploited to improve the production of target proteins, the expression of which is driven by xylanolytic promoters. In this regard, the $\mathrm{creA}^{d} 30 \mathrm{mu}-$ tation has been shown to result not only in considerably elevated transcript levels of the xylanolytic genes under inducing conditions but also in elevated levels of extracellular xylanase activity [29,30]. This could well be a result of the derepression of the regulatory gene $x \ln R[18]$. 
Here we optimize the performance of the A. nidulans xylanolytic $\left(\mathrm{XlnR}-x \ln _{\mathrm{p}}\right)$ system to overproduce recombinant proteins. We chose endogenous xylanases and the Aspergillus aculeatus $\alpha$-L-rhamnosidase RhaA as representatives because of their commercial potential in the biofuel, food and feed industries among others [31-33]. Improvements in the production of these enzymes by means of engineering the expression of transcription factors regulating $x \ln A$ and $x \ln B(\mathrm{X} \ln \mathrm{R}$ and $\mathrm{PacC})$ is reported. To the best of our knowledge there has been no systematic evaluation of the effect of engineering PacC function (alone or in combination with pathway-specific regulators) to enhance protein yields in fungi.

\section{Results and discussion}

\section{CreA-independent overexpression of the xylanolytic} activator XInR leads to enhanced production of native xylanases in $A$. nidulans

It has been previously shown that the three characterized $A$. nidulans xylanolytic genes $(x \ln A-C)$ are overexpressed under inducing conditions $(1 \% \mathrm{w} / \mathrm{v}$ xylose $)$ in the $\operatorname{gpd} A_{\mathrm{p}}: x \ln R$ genetic background (that is, where the regulatory gene $x \ln R$ is overexpressed in a CreAindependent fashion) [18]. To evaluate whether this manipulation of the expression of $x \ln R$ also leads to enhanced protein production from XlnR-regulated promoters we first compared the kinetics of xylanase production in $x \ln R^{+}$(AR70) and $g p d A_{\mathrm{p}}:: x \ln R$ (AR66 and AR67) isogenic strains, as well as in the reference strain biA1 (AR5). Extracellular xylanase activity was determined at 4, 24, 48 and 72 hours after mycelia transfer to inducing conditions. A dramatic increase in xylanase yields during the time course of the experiment was found in the $g p d A_{\mathrm{p}}:: x \ln R$ strains, relative to controls (Figure 1). The maximum level of extracellular xylanase activity in these $\mathrm{X} \ln R$ engineered strains was achieved after 24 hours of cultivation in the presence of xylose, corresponding to an approximately 10 -fold increase compared to controls. Interestingly, about $75 \%$ of the maximum activity reached by AR66 and AR67 was attained 4 hours after transfer; at this time, extracellular xylanase activity in AR70 and biA1 was about 200-fold lower. This rapid enhancement of xylanase production in the $g p d A_{\mathrm{p}}:: x \ln R$ strains has the additional biotechnological advantage of cost savings as a result of reduced production times. Moreover, with shorter times the presence of undesirable proteins such as proteases can be expected to be lower than at later stages of culture since they are produced in response to nutrient limitation [34]. As expected, similar kinetics and yields were attained in each strain pair (AR66 and AR67 on one hand and the two control strains biA1 and AR70 on the other). In addition, xylanase activities per mg of total extracellular protein were calculated from the volumetric activity data. A notable difference between the $g p d A_{\mathrm{p}}: x \ln R$ and $x \ln R^{+}$strains was also observed at 4 and 24 hours (about 49- and 11-fold increases respectively) thus ruling out the possibility that the increases in xylanase activity were simply due to an overall increase in extracellular protein accumulation.

The improvement in xylanase yields achieved in $A$. nidulans is greater than that reported for Penicillium canescens in which transformants with an altered copy

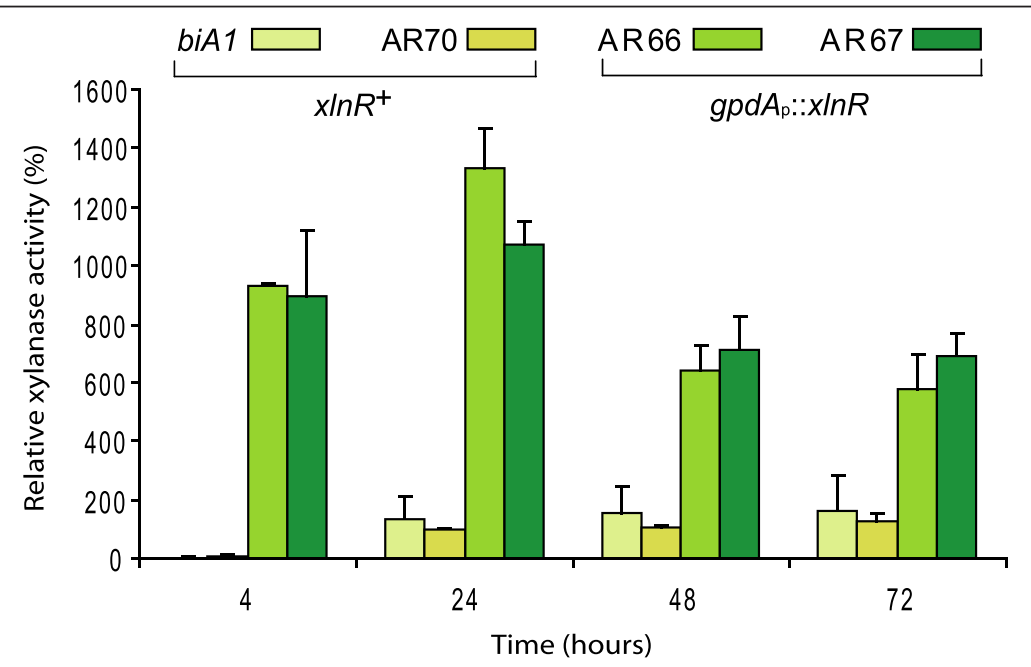

Figure 1 Effect of the $g p d A_{\mathrm{p}}:: x \ln R$ genetic background on native xylanase activity. Time course analysis of the extracellular xylanase activities in $g p d A_{p}:: x \ln R$ strains (AR66 and AR67) and controls (wild type biA1 and the nutritional arginine prototrophic control AR70). AR66, AR67 and $A R 70$ are isogenic strains bearing respectively one copy of plLJ16_gpdA $A_{p}: x \mid \ln R$ or plLJ16 integrated at the $\arg B$ locus. The mycelia were grown under non-repressing, non-inducing conditions ( $0.1 \% \mathrm{w} / \mathrm{v}$ fructose) before being transferred to inducing conditions (1\% w/v xylose), and samples were collected at the time points indicated. Values (means \pm standard deviation (SD)) are expressed as percentages and referred to that of the AR70 strain at 24 hours. For each strain, two independent experiments with two independent cultures were carried out. 
number of the $x \ln R$ regulatory gene expressed from its own promoter produced up to six times more activity than the wild type [35]. Xylanase production in xylan cultures of a $T$. reese $i$ strain constitutively expressing the xylanolytic activator Xyr1 was also shown to be greater than that of the wild type at relatively early culture stages (about four times after 48 hours), though the maximum levels of activity achieved by both strains were similar after 72 hours [36]. Characteristics specific to each fungal species (for example protein folding, secretory ability and protease activity), differences in $\mathrm{X} \ln \mathrm{R} / \mathrm{Xyr} 1$ expression levels, different requirements for XlnR/Xyr1 of the xylanolytic gene promoters and/or differences in the culture conditions (such as the use of distinct inducers) might account for the differences in improvements reported in each study.

\section{The intrinsic efficiency of $x \ln A_{\mathrm{p}}$ in driving the expression} of heterologous glycosyl hydrolases is greater than that of $x \ln B_{\mathrm{p}}$

In order to investigate the potential of the A. nidulans xylanolytic system $\left(\mathrm{X} \operatorname{lnR}-x \ln n_{\mathrm{p}}\right)$ for the production of heterologous proteins, the well-characterized promoters of the $x \ln A$ and $x \ln B$ genes $\left(x \ln A_{\mathrm{p}}\right.$ and $\left.x \ln B_{\mathrm{p}}\right)$ were chosen [18,25-27] and the rhaA gene from $A$. aculeatus that encodes an extracellular $\alpha$-L-rhamnosidase of industrial interest [37] was used as a reporter.

Two expression vectors (pILArhaA and pILBrhaA) comprising in-frame translational fusions of $x \ln A_{\mathrm{p}}$ and $x \ln B_{\mathrm{p}}$ (respectively) with the $A$. aculeatus rhaA gene were generated (Additional file 1: Figure S1A and $\mathrm{B}$ ) and used independently to transform the $A$. nidulans arginine auxotrophic strain AR4 (argB2, metG1, biA1). Arginine prototrophic transformants were selected and tested for $\alpha$-L-rhamnosidase activity on minimal medium (MM)-xylose plates supplemented with the substrate 4-methylumbelliferyl $\alpha$-L-rhamnopyranoside (MUR). A total of 18 transformants of pILArhaA and 50 of pILBrhaA were analyzed by Southern blot analysis (Additional file 1: Figure S1C and D). To minimize positional effects that could affect regulatory mechanisms controlling these promoters, transformants carrying single-copy integrations of the expression vectors at the homologous $x \ln A$ and $x \ln B$ loci were selected. Two strains (AR137 and AR138), each bearing a single copy of the $x \ln A_{\mathrm{p}}::$ rha $A$ expression cassette integrated at the $x \ln A$ locus, and two strains (AR142 and AR143) carrying one copy of $x \ln B_{\mathrm{p}}:$ rh $a A$ located in the $x \ln B$ locus were chosen for further analyses. $\alpha$-L-rhamnosidase plate assays confirmed $r h a A$ induction by xylose and wild type responses to ambient $\mathrm{pH}$ in all (not shown).

The performance of these four recombinant strains was studied by measuring extracellular $\alpha$-L-rhamnosidase activity under inducing conditions. Xylan from oat spelts (OSX) was used as the sole carbon source. Given that full induction of the $x \ln A$ gene requires alkaline growth conditions, whereas that of $x \ln B$ mainly occurs at acidic $\mathrm{pH}$ values [25], mycelia grown for 18 hours in fructose $(0.1 \% \mathrm{w} / \mathrm{v})$ were transferred to fresh media buffered to $\mathrm{pH} 8$ (AR137 and AR138) or $\mathrm{pH} 5.5$ (AR142 and AR143) containing 1\% (w/v) OSX and incubated for 6 more days. As seen in Figure 2, extracellular

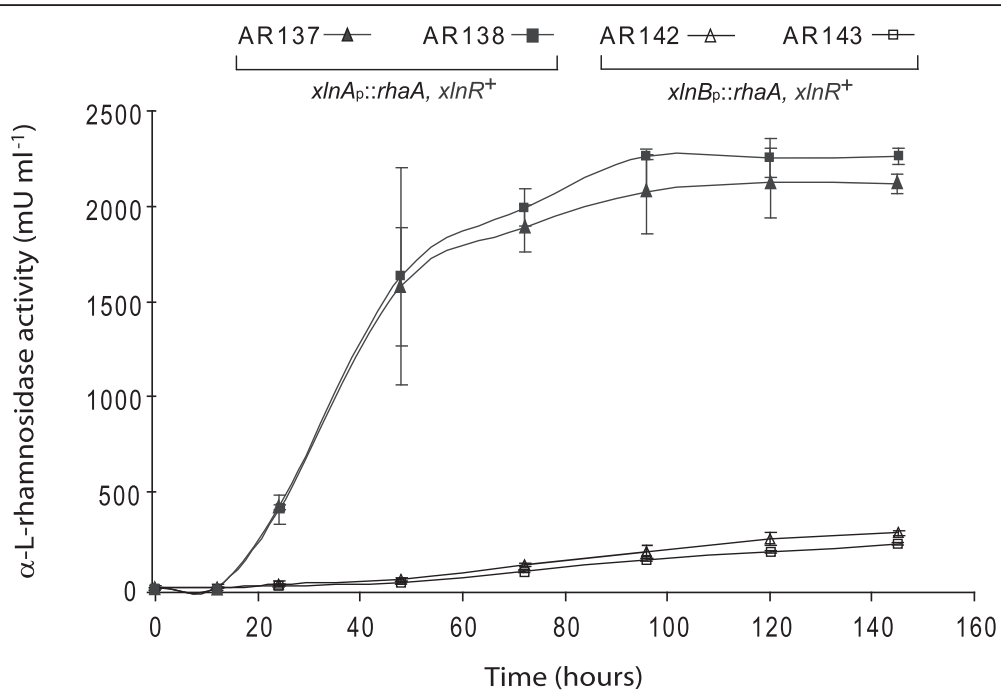

Figure 2 Intrinsic yield potential of $x \ln A_{\mathrm{p}}$ and $x \ln B_{\mathrm{p}}$ for the production of heterologous proteins. Time course analysis of extracellular a-L-rhamnosidase activities produced by $x \ln A_{p}:$ :rhaA (AR137 and AR138) and $x \ln B_{p}::$ rhaA (AR142 and AR143) strains. The mycelia were grown under non-repressing, non-inducing conditions ( $0.1 \% \mathrm{w} / \mathrm{v}$ fructose) before being transferred to their specific inducing conditions ( $1 \% \mathrm{w} / \mathrm{v}$ oat spelt xylan (OSX) alkaline or acidic), and samples were collected at the time points indicated. Values $\left(\mathrm{mU} \mathrm{ml}{ }^{-1}\right)$ are presented as means \pm SD. For each strain, at least two independent cultures were carried out. 
$\alpha$-L-rhamnosidase activity reached values about 8.5 -fold higher in the $x \ln A_{\mathrm{p}}:: r h a A$ strains compared to those carrying $x \ln B_{\mathrm{p}}:$ :rhaA $\left(2116 \mathrm{mU} \mathrm{ml}^{-1}\right.$ AR137; $2262 \mathrm{mU} \mathrm{ml}^{-1}$ AR138 versus $288 \mathrm{mU} \mathrm{ml}^{-1}$ AR142; $228 \mathrm{mU} \mathrm{ml}^{-1}$ AR143). $\alpha$-L-rhamnosidase production was also faster in the $x \ln A_{\mathrm{p}}::$ rhaA strains. The maximum activity produced by AR137 and AR138 was achieved between 72 and 96 hours after mycelial transfer to inducing conditions, whereas that of the $x \ln B_{\mathrm{p}}::$ rhaA strains (AR142 and AR143) was achieved after 120 hours. This concords with previous observations in which the $x \ln A$ transcript was seen to accumulate to a greater level under inducing conditions than that of $x \ln B$ [18,25-27]. Therefore, in a wild type genetic background under these experimental conditions the $x \ln A$ gene promoter is more effective for heterologous protein production than $x \ln B_{\mathrm{p}}$. As expected, each strain pair (AR137 and AR138 on one hand and AR142 and AR143 on the other) behaved similarly. To discount the possibility of endogenous $\alpha$-L-rhamnosidase activity in these culture conditions, strain AR70 (which carries a single copy of the empty vector pILJ16 integrated at the $\arg B$ locus of AR4 (R. Luque and M. Orejas unpublished work)) was grown under the same experimental conditions. No $\alpha$-L-rhamnosidase activity was detected.

Bearing in mind that the $\mathrm{pH}$ of the culture medium could influence the stability, activity and/or interactions of secreted proteins, the $A$. nidulans $x \ln A_{\mathrm{p}}$ and $x \ln B_{\mathrm{p}}$ promoters provide an additional advantage in facilitating protein production in response to the ambient $\mathrm{pH}$, thereby potentially widening the portfolio of recombinant enzymes that can be synthesized depending on their optimal $\mathrm{pH}$ values. Nevertheless, the poor performance of $x \ln B_{\mathrm{p}}$ (compared to $x \ln A_{\mathrm{p}}$ ) indicates that further improvements need to be made with this promoter before it can be used to obtain comparable yields of recombinant enzymes.

\section{CreA-independent overexpression of $x \ln R$ enhances the activity of $x \ln A_{p}$ and $x \ln B_{p}$ for heterologous protein production}

Previous work revealed considerably increased accumulation of both the $x \ln A$ and $x \ln B$ transcripts in $A$. nidulans $g p d A_{\mathrm{p}}:: x \ln R$ mutant strains compared to the wild type [18]. Xylanase activity is also greatly enhanced in this genetic background (Figure 1). These data strongly suggest that wild type expression of $x \ln R$ would thus constitute a bottleneck for heterologous protein production when driven by the corresponding $A$. nidulans XlnR-regulated promoters $\left(x \ln A_{\mathrm{p}}\right.$ and $\left.x \ln B_{\mathrm{p}}\right)$. To address this, strains $x \ln A_{\mathrm{p}}:: r h a A, \operatorname{gpd} A_{\mathrm{p}}:: x \ln R$ (AR210 and AR211) and $x \ln B_{\mathrm{p}}::$ $r h a A, \operatorname{gpd} A_{\mathrm{p}}:: x \ln R$ (AR201 and AR206) were generated by means of sexual crosses (see the Methods section) and $\alpha$-L-rhamnosidase activities driven from both promoters were compared between $g p d A_{\mathrm{p}}:: x \ln R$ and $x \ln R^{+}$ genetic backgrounds. In agreement with the positive effect shown on xylanase activity, $\alpha$-L-rhamnosidase activity was enhanced in the $g p d A_{\mathrm{p}}:: x \ln R$ engineered strains and found to peak earlier under inducing conditions (OSX, and alkaline or acidic buffered media). The maximum levels of RhaA activity reached by AR210 and AR211 (4535 mU ml ${ }^{-1}$ AR210; $3920 \mathrm{mU} \mathrm{ml}^{-1}$ AR211) approximately doubled that of the $x \ln R^{+}$strain AR137 (2100 $\mathrm{mU} \mathrm{ml}^{-1}$; Figure 3A), and this was achieved in the period of 48 to 72 hours rather than 72 to 96 hours. Remarkably, the yields of $\alpha$-L-rhamnosidase activity reached with the $x \ln B_{\mathrm{p}}:: r h a A, g p d A_{\mathrm{p}}:: x \ln R$ strains (2757 $\mathrm{mU} \mathrm{ml}^{-1}$ for AR201; $2364 \mathrm{mU} \mathrm{ml}^{-1}$ for AR206) were about 10-fold greater than those for AR142 $\left(x \ln B_{\mathrm{p}}:: r h a A, x \ln R^{+} ; 254 \mathrm{mU} \mathrm{ml}^{-1}\right)$, the differences in production being greater at shorter times (19-fold after 72 hours) when $84 \%$ of the total activity had already been produced (Figure 3B). Levels of RhaA activity in relation to total extracellular protein (Figure $3 \mathrm{C}$ ) throughout the course of the experiment were also greater in the $g p d A_{\mathrm{p}}:: x \ln R$ mutants compared to the $x \ln R^{+}$strains, which is consistent with the contribution of deregulated $\mathrm{X} \ln \mathrm{R}$ overexpression to this enhancement. At the periods where volumetric RhaA activities peaked the average specific activities of AR210 and AR211 (14604 \pm 1234 and $13755 \pm 657 \mathrm{mU} \mathrm{mg}^{-1}$ at 48 and 72 hours, respectively) were about 1.6-fold greater than those of AR137 $\left(9248 \pm 1373\right.$ and $8366 \pm 690 \mathrm{mU} \mathrm{mg}^{-1}$, respectively). In addition, at 72 and 96 hours the average specific activities of AR201 and AR206 (12860 \pm 1406 and $13416 \pm 986 \mathrm{mU} \mathrm{mg}^{-1}$, respectively) were about 10 -fold greater than those of AR142 (1186 \pm 199 and $1458 \pm 218$ $\mathrm{mU} \mathrm{mg}^{-1}$, respectively).

Of note is the considerable delay in attaining the maximum yield of $\alpha$-L-rhamnosidase activity in the $\operatorname{gpd} A_{\mathrm{p}}:: x \ln R$ genetic backgrounds compared to that of the xylanase activity produced by the $g p d A_{\mathrm{p}}:: x \ln R$ strains AR66 and AR67 which reached 75\% of their maximum level just four hours after mycelial transfer to inducing conditions. This difference is probably associated with the nature of the inducing carbon sources used for each experiment: the cultures of AR66 and AR67 were performed in minimal medium with xylose $(1 \% \mathrm{w} / \mathrm{v})$, whereas the production of $\alpha$-L-rhamnosidase was studied in the presence of OSX $(1 \% \mathrm{w} / \mathrm{v})$. The increased levels of extracellular $\alpha$-L-rhamnosidase activity associated with the $g p d A_{\mathrm{p}}:: x \ln R$ genetic background shows that the expression of $x \ln R$ is also a limiting factor for $x \ln A$ and $x \ln B$ expression in the presence of xylan. That $\mathrm{X} \ln R$ overexpression has a stronger positive effect on $x \ln B_{\mathrm{p}}$ than on $x \ln A_{\mathrm{p}}$ suggests that the $\mathrm{X} \ln \mathrm{R}$ binding sites on $x \ln B_{\mathrm{p}}$ are less responsive to the limiting amounts of this transcriptional factor present in the wild type genetic background. Since it has been shown that CreA-mediated repression of $x \ln B$ occurs indirectly 

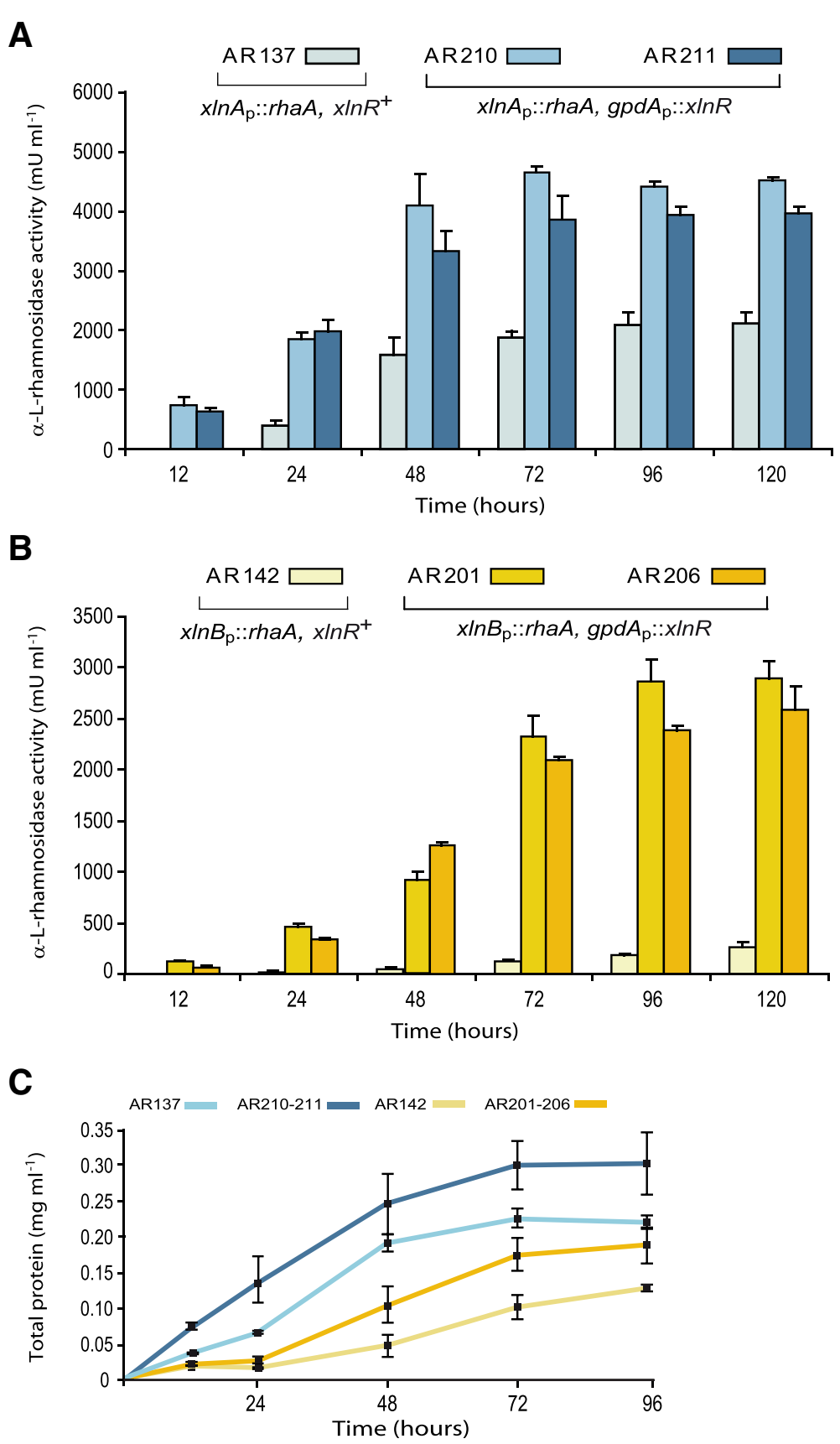

Figure 3 Effect of the $\mathbf{g p d} \boldsymbol{A}_{\mathbf{p}}:: x \ln R$ background on extracellular a-L-rhamnosidase activity. (A) $x \ln A_{\mathrm{p}}::$ : $h a A, g p d A_{p}:: x \ln R$ strains (AR210 and AR211) and (B) $x \ln B_{p} .: \cdot r h a A, g p d A_{p}:: x \ln R$ strains (AR201 and AR206). AR137 and AR142 were respectively used as reference strains. AR137, AR210 and AR211 were grown under non-repressing, non-inducing conditions ( $0.1 \% \mathrm{~W} / \mathrm{v}$ fructose) before being transferred to inducing conditions (1\% w/v OSX, pH 8). AR142, AR201 and AR206 were grown in 0.1\% w/v fructose before being transferred to inducing conditions (1\% w/v OSX, pH 5.5). Samples were collected at the time indicated. Values $\left(\mathrm{mU} \mathrm{ml}^{-1}\right)$ are presented as means \pm SD. (C) Comparison of extracellular protein levels $\left(\mathrm{mg} \mathrm{ml}^{-1}\right)$ accumulated by the $x \ln R$ engineered strains. For each strain, at least two independent cultures were carried out.

through a transcriptional regulatory cascade via $x \ln R$ repression [18], complete CreA-mediated derepression can be expected for $x \ln B_{\mathrm{p}}$ in $g p d A_{\mathrm{p}}: x \ln R$ genetic backgrounds. Hence the use of $\triangle c r e A$ or $c r e A^{\mathrm{d}} 30$ mutant derepressed backgrounds as a means to obtain an additional positive effect on $x \ln B_{\mathrm{p}}$ activity was not considered.
Introducing the palA1 allele into $g p d A_{\mathrm{p}}:: x \ln R$ strains expressing rhaA under the control of $x \ln B_{\mathrm{p}}$ further enhances $a$-L-rhamnosidase yields

As noted above, expression of the $A$. nidulans $x \ln B$ gene is regulated in response to ambient $\mathrm{pH}$ via the wide domain transcription factor PacC. Interestingly, acidity-mimicking 
mutations (such as palA1) in the $\mathrm{pH}$-sensing transduction pathway resulted in a greater elevation of the levels of $x \ln B$ expression compared to those reached by the wild type strain grown at acidic $\mathrm{pH}$ values [25]. As different mutations could act synergistically, the improvements seen in the level of RhaA activity resulting from the expression of the $x \ln B_{\mathrm{p}}:: r h a A$ cassette in $g p d A_{\mathrm{p}}:: x \ln R$ mutant strains encouraged us to explore the effect of combining this genetic background with the palA1 mutation.

Strains of genotype $x \ln B_{\mathrm{p}}:: \operatorname{rhaA}, g p d A_{\mathrm{p}}:: x \ln R$, palA1 (AR207 and AR208) were obtained by means of genetic crosses (see the Methods section). Fructose-grown mycelia $(0.1 \%)$ were transferred to buffered acidic media containing OSX (1\%), and the kinetics of extracellular $\alpha$-L-rhamnosidase activity of these strains was compared to that of AR206 $\left(x \ln B_{\mathrm{p}}:: r h a A, g p d A_{\mathrm{p}}:: x \ln R, p a l A^{+}\right)$. Figure 4 shows that, under inducing conditions, the maximum level of $\alpha$-L-rhamnosidase activity in the palA1 strains (4124 $\mathrm{mU} \mathrm{ml}^{-1}$ AR207; $3583 \mathrm{mU} \mathrm{ml}^{-1}$ AR208) was about 1.7-fold greater than that in AR206 $\left(\mathrm{palA}^{+}\right)$and was also reached earlier (between 48 and 72 hours instead at 96 hours). Differences in RhaA production between $g p d A_{\mathrm{p}}:: x \ln R$, palA $A^{+}$and $g p d A_{\mathrm{p}}:: x \ln R$, palA1 strains are even greater at earlier times, that is, 14-, 4.3- and 2.7-fold higher after 12, 24 and 48 hours respectively. After 48 hours, $87 \%$ of the total activity has already been produced.

The extracellular $\alpha$-L-rhamnosidase titers achieved by AR207 or AR208 (approximately $1300 \mathrm{mU} \mathrm{ml}^{-1}$ $13000 \mathrm{mU} \mathrm{mg}^{-1}$ ) and AR210 or AR211 (approximately $1900 \mathrm{mU} \mathrm{ml}^{-1} ; 15000 \mathrm{mU} \mathrm{mg}^{-1}$ ) after 24 hours are 2- to 3 -fold greater than those reported for the endogenous rhamnosidase(s) (approximately $588 \mathrm{mU} \mathrm{ml}^{-1}$; $9300 \mathrm{mU}$ $\mathrm{mg}^{-1}$ ) after 24 hours of growth in L-rhamnose [38] and 10- to 15-fold higher than the maximum levels produced by a Saccharomyces cerevisiae strain overexpressing the same rhaA gene from a high copy number plasmid (approximately $130 \mathrm{mU} \mathrm{mL}^{-1} ; 2600 \mathrm{mU} \mathrm{mg}^{-1}$ ) [37]. In addition, the $\alpha$-L-rhamnosidase maximum yields produced by the engineered strains AR207 and AR208 (approximately $3800 \mathrm{mU} \mathrm{ml}^{-1} ; 15400 \mathrm{mU} \mathrm{mg}^{-1}$ ), and AR210 and AR211 (approximately $4260 \mathrm{mU} \mathrm{ml}^{-1}$; $13800 \mathrm{mU} \mathrm{mg}^{-1}$ ) were greater than those reported for commercial preparations of $A$. niger $\left(570 \mathrm{mU} \mathrm{mg}^{-1}\right.$ ) [39] and A. aculeatus (13000 mU mg ${ }^{-1}$ ) [40]. It should be mentioned that these filamentous fungi have multiple $\alpha$-L-rhamnosidase genes. The expression of $r h a A$ in the engineered $A$. nidulans $\mathrm{X} \operatorname{lnR}-x \ln n_{\mathrm{p}}$ system also provides a more economical means of induction (xylose or xylan instead of L-rhamnose) which may be especially relevant in the case of large-scale fermentations. The possibility of using hemicellulosic hydrolysates as inducers could also reduce production costs even more. Since carbon catabolite repression (CCR) is a challenge to overcome when plant hydrolysates are used as both substrates for growth and as inducing carbon sources, CreA-independent expression of engineered $x \ln B_{\mathrm{p}}:: \operatorname{rh} a A, g p d A_{\mathrm{p}}: x \ln R$, palA1 ${ }^{-}$strains could facilitate the use of less preferred carbon sources such as xylose in the presence of glucose.

These results clearly demonstrate the potential of engineering the expression $(\mathrm{X} \ln \mathrm{R})$ or activity $(\mathrm{PacC})$ of key regulators of the $A$. nidulans xylanolytic system to dramatically enhance the production of heterologous glycosyl hydrolases and, by extension, other proteins.

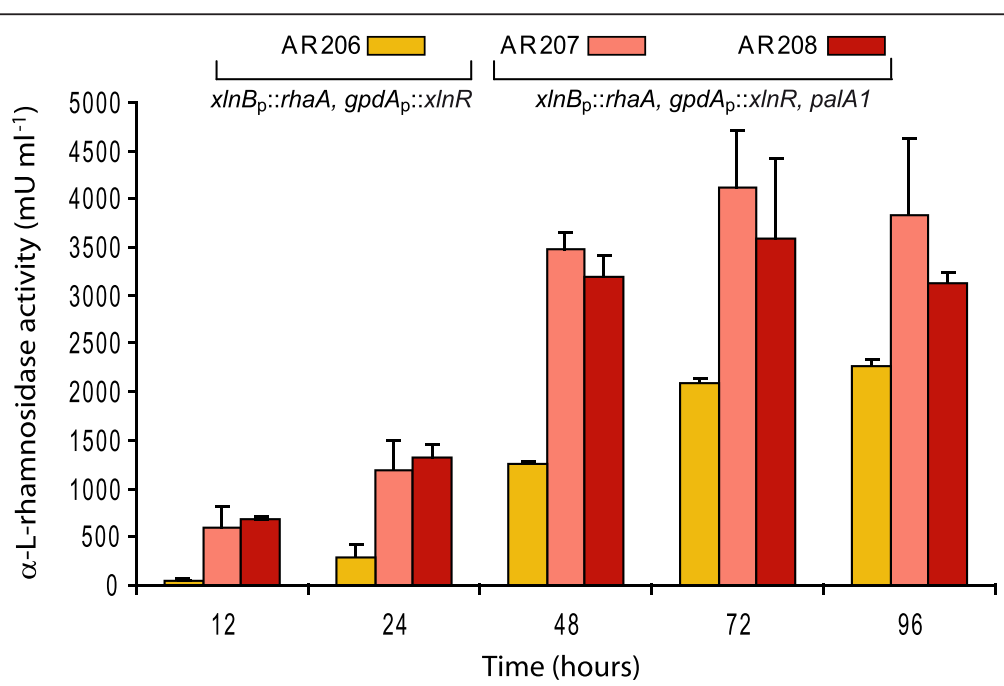

Figure 4 Effect of the palA1 mutation on extracellular a-L-rhamnosidase activity produced by $x \ln B_{\mathrm{p}}:: r h a A, g p d A_{\mathrm{p}}:: x \ln R$ strains. Bar

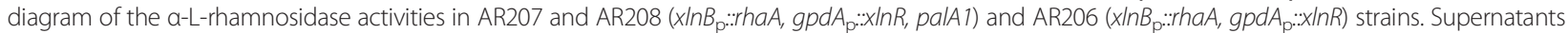
of the indicated strains were obtained after grown in $1 \% \mathrm{~W} / \mathrm{V}$ OSX pH 5.5 at the time indicated. Values $\left(\mathrm{mU} \mathrm{m}^{-1}\right)$ are presented as means \pm SD. For each strain, at least two independent cultures were carried out. 
The activity of the $x \ln B$ promoter in the engineered palA1, gpd $A_{\mathrm{p}}:: x \ln R, x \ln B_{\mathrm{p}}::$ :rhaA strains remains dependent on the presence of the inducer

Through the combination of different mutations affecting regulatory genes that control the expression of the $A$. nidulans xylanolytic system it has been possible to enhance the efficiency of the $x \ln B$ gene promoter. To assess whether $x \ln B_{\mathrm{p}}$ is still a regulated promoter in gpd $A_{\mathrm{p}}:: x \ln R$, palA1 genetic backgrounds, the levels of $\alpha$-L-rhamnosidase activity produced by AR207 in the presence or absence of an inducing carbon source were analyzed. AR207 was grown in MM with $0.1 \%$ fructose for 18 hours, transferred to $1 \%$ OSX or $1 \%$ glucose media, and extracellular $\alpha$-L-rhamnosidase activity was evaluated during the 72 hours after mycelium transfer. As shown in Figure 5, $\alpha$-L-rhamnosidase activity was almost undetectable in cultures containing glucose as the sole carbon source, reaching at most $1 \%$ of the maximum activity produced in xylan cultures even at late culture times when glucose is depleted. This result clearly indicates that the protein expression system based on $\mathrm{X} \ln R-x \ln B_{\mathrm{p}}$ in the genetic background $g p d A_{\mathrm{p}}: x \ln R$, palA1 does not obviate the requirement for the inducer and could be used to express genes the products of which could otherwise compromise fungal growth.

\section{Conclusions}

In this study a transcription factor engineering approach for strain improvement was successfully applied to the A. nidulans $\mathrm{X} \operatorname{lnR}:: x \ln _{\mathrm{p}}$ expression system. Specifically, the $x \ln R$ gene was overexpressed from the strong constitutive promoter of the gpdA gene (instead of from its own weak and CreA-repressed promoter), and this was combined with a second modification altering the activity of the $\mathrm{pH}$ master regulator PacC. Overall, improvements were manifest in the yield of endogenous xylanases and reduced production times. Engineering $\mathrm{X} \ln \mathrm{R}$ expression and PacC activity has also been shown to have a considerable impact on heterologous protein production. These results highlight the potential of $A$. nidulans for development as an efficient 'mycofactory' and the importance of engineering transcription factors as a key strategy in achieving overproduction.

\section{Methods}

\section{Strains and growth conditions}

Escherichia coli DH5 $\alpha$ (endA1, hsdR17, gyrA96, thi-1, relA1, supE44, recA1, $\triangle$ lacU169 (Ф80 lacZAM15)) was used for cloning experiments and plasmid propagation. It was grown in Luria Broth (LB) medium (1\% w/v tryptone, $0.5 \% \mathrm{w} / \mathrm{v}$ yeast extract, $1 \% \mathrm{w} / \mathrm{v} \mathrm{NaCl}$ ) with or without $100 \mu \mathrm{g} \mathrm{ml}^{-1}$ ampicillin. For solid media $1.5 \% \mathrm{w} / \mathrm{v}$ agar was added. A. nidulans strains used in this study are described in Table 1. These strains were grown in either minimal (MM) or complete (CM) media $[41,42]$ containing $1 \% \mathrm{w} / \mathrm{v}$ of the carbon source unless specified otherwise, and supplemented with appropriate requirements. CM agar-plates were used to generate $A$. nidulans spores. For enzyme production, mycelial biomass was generated from spores inoculated in MM supplemented with $0.09 \% \mathrm{w} / \mathrm{v}$ ammonium tartrate as the nitrogen source, to which $0.1 \%$ $\mathrm{w} / \mathrm{v}$ fructose was added as the sole carbon source, with a final $\mathrm{pH}$ value of 6.5. After 18 hours of growth, mycelia were harvested, washed with MM without a carbon source and transferred to the induction media. Induction media was prepared by substituting fructose with either D-xylose or OSX, both at $1 \% \mathrm{w} / \mathrm{v}$. Acidic MM (buffered with $100 \mathrm{mM}$ monosodium phosphate plus $100 \mathrm{mM} \mathrm{NaCl}$ ) was used to optimize $x \ln B_{\mathrm{p}}$ performance, whereas alkaline MM (buffered with $100 \mathrm{mM}$ disodium phosphate) was used to optimize $x \ln A_{\mathrm{p}}$ [25]. When needed, $1 \% \mathrm{w} / \mathrm{v}$ glucose was used. All the chemicals used were purchased

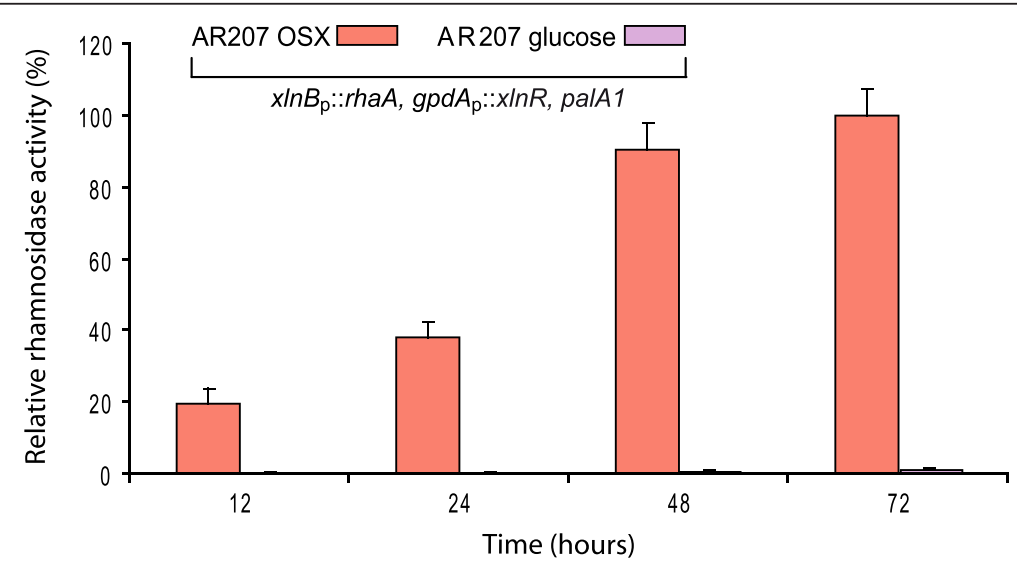

Figure $5 x \ln B_{\mathrm{p}}::$ rhaA, $g p d A_{\mathrm{p}}:: x \ln R$, palA1 strains are still highly dependent on the presence of the inducer. Comparison of the extracellular RhaA activities produced by the AR207 strain grown in $1 \% \mathrm{w} / \mathrm{V}$ OSX pH 5 or $1 \% \mathrm{w} / \mathrm{V}$ glucose $\mathrm{pH}$ 5. Values $\left(\mathrm{mU} \mathrm{m}^{-1}\right)$ are expressed as percentages (means \pm SD) and referred to that obtained after 72 hours on OSX. For each strain, two independent cultures were carried out. 
Table 1 List of $A$. nidulans strains used in this study

\begin{tabular}{|c|c|c|}
\hline Strain & Relevant genotype & Source \\
\hline AR4 & $\arg B 2$, metG1, biA1 & MA Peñalva (CIB/CSIC) (lab strain) \\
\hline AR5 & biAl & MA Peñalva (lab strain) \\
\hline AR66; AR67 & {$\left[g p d A_{p}:: x \ln R / p \mid L 16\right]-\operatorname{argB2}, \operatorname{metG1}$, biA1 } & [18] \\
\hline AR70 & metG1, biA1, [plLJ16]-argB2 & M Orejas (unpublished work) \\
\hline AR83 & pabaA1, yA2, argB2, pacC 14 & E Espeso (CIB/CSIC) (lab strain) \\
\hline AR137; AR138 & {$\left[x \mid n A_{p}:: x h a A\right]-x \mid n A, \arg B 2, \operatorname{met} G 1, b i A 1$} & This study \\
\hline AR142; AR143 & {$\left[x \ln B_{\mathrm{p}}:: r h a A\right]-x \ln B, \arg B 2, \operatorname{metG} 1, b i A 1$} & This study \\
\hline AR152 & {$\left[x \mid n A_{p}:: r h a A\right]-x \ln A, p a b a A 1, b i A 1, p^{2} C^{C} 14$} & This study \\
\hline AR181 & $\arg B 2, p a b a A 1, y A 2, p a l A 1$ & E Espeso (lab strain) \\
\hline AR187 & {$\left[x \ln B_{p}:: r h a A\right]-x \mid n B, p a b a A 1, y A 2$, palA1 } & This study \\
\hline AR201 & {$\left[x \ln B_{p}:: r h a A\right]-x \ln B,\left[g p d A_{p}:: x \ln R\right]-\arg B 2$, biA1 } & This study \\
\hline AR206 & {$\left[x \ln B_{p}:: r h a A\right]-x \ln B,\left[g p d A_{p}:: x \ln R\right]-\arg B 2, \operatorname{metG} 1$, biA1 } & This study \\
\hline AR207 & {$\left[x \ln B_{p}:: r h a A\right]-x \ln B,\left[g p d A_{p}:: x \ln R\right]-\arg B 2, p a b a A 1, y A 2$, palA1 } & This study \\
\hline AR208 & {$\left[x \ln B_{p}:: r h a A\right]-x \ln B,\left[g p d A_{p}: x \ln R\right]-\arg B 2, \operatorname{met} G 1, p a b a A 1, y A 2$, palA1 } & This study \\
\hline AR210 & {$\left[x \ln A_{p}:: r h a A\right]-x \ln B,\left[g p d A_{p}:: x \ln R\right]-\arg B 2, p a b a A 1$, biA1 } & This study \\
\hline AR211 & {$\left[x \ln A_{p}:: r h a A\right]-x \ln A,\left[g p d A_{p}:: x \ln R\right]-\arg B 2$, biA 1} & This study \\
\hline
\end{tabular}

from Conda-Pronadisa (Torrejón de Ardoz, Madrid, Spain), Panreac-Química (Castellar del Vallés, Barcelona, Spain) and Sigma-Aldrich (St. Louis, MO, USA), unless otherwise stated.

\section{DNA manipulations and transformations}

E. coli plasmid isolation was performed using the GenElute plasmid miniprep kit (Sigma-Aldrich, St. Louis, MO, USA). Other general DNA manipulations were performed as described [43]. Transformation of the A. nidulans strain AR4 was carried out as described previously [44]. Restriction enzymes, Expand High Fidelity system, and T4 DNA ligase were purchased from Roche (Roche Diagnostics, Mannheim, Germany) and used as recommended by the manufacturer. Nucleic acid hybridization for Southern analyses was made using Hybond- $\mathrm{N}^{+}$membranes (GE Healthcare, Little Chalfont, UK). DNA probes were labelled using the digoxigenin (DIG) DNA Labeling Kit (Roche). DNA sequencing was carried out using the BigDye Terminator v3.1 Cycle Sequencing Kit (Applied Biosystems, Warrington, UK) and the ABI PRISM 310 Genetic Analyzer (Applied Biosystems) at the DNA Sequencing Service of the University of Valencia. Chromatograms were analyzed using the program Chromas LITE 2.01(http://technelysium. com.au). Oligonucleotides used in the present study are listed in Table 2.

Construction of plasmids expressing rhaA of $A$. aculeatus under the control of the $x \ln A$ and $x \ln B$ gene promoters Promoter regions of $x \ln A(1480 \mathrm{bp}$ before the ATG codon; $\left.x \ln A_{\mathrm{p}}\right)$ and $x \ln B\left(1815\right.$ bp before the ATG; $\left.x \ln B_{\mathrm{p}}\right)$ were obtained by polymerase chain reaction (PCR) from plasmids pBA7.1 and pEA8.1 respectively [45]. XAKpn and XAXhoII oligonucleotides were used to amplify $x \ln A_{\mathrm{p}}$ whereas XBKpn and XBXhoII for $x \ln B_{\mathrm{p}}$. Primers XAKpn and XBKpn were designed with an artificial KpnI site at the 5 ' end. XAXhoII and XBXhoII were designed with an additional sequence of 21 nucleotides that encode the 7 first amino acids of RhaA from $A$. aculeatus, and including an artificial BamHI site at the 5 ' end, compatible with the XhoII site present in rhaA. A 381 bp fragment corresponding to the $5^{\prime}$ end of the rhaA open reading frame (ORF) was also amplified by PCR from plasmid pR22 (M. Orejas, unpublished work) using primers RhaATG and Rha381, and it was cloned into the pGEM T-Easy vector (Promega, Madison, WI, USA) generating

Table 2 List of primers used in this study

\begin{tabular}{ll}
\hline Name & Sequence $\mathbf{( 5 '}^{-3} \mathbf{3}^{\mathbf{a}}$ \\
\hline XAKpn & tcttgagctcggtaccTTGACTGTACAATCATG \\
XAXholl & ctcaggatccAGGATGACCACAACATTGTGCTGATCCTG \\
XBKpn & tcttgagctcggtaccAATTCGAAAAGGTAG \\
XBXholl & ctcaggatccAGGATGACCACAACATGTTGCCGGTTGTTG \\
RhaATG & AACCAGCTGTGGTCATCCTGGATC \\
Rha381 & aacaaagcttCCTGGTCCATGGCC \\
PacC923dir & CTGTGGCTGTTGCTAGTGGTCC \\
PacC1650rev & CCGAGTACATCATCCTCGCCC \\
GpdAXho & CCTTCAGTGGACTCGAGTACC \\
XInRECO & ccgaattcTATACAATGCGC \\
\hline
\end{tabular}

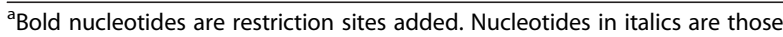
coding for the seven first amino acids of RhaA. Capital letters indicate the nucleotides complementary to the genes. 
pGEM-frhaA. The primer Rha381 contains an artificial HindIII site to allow an additional cloning step.

$x \ln A_{\mathrm{p}}$ and $x \ln B_{\mathrm{p}}$ PCR fragments were digested with $K p n \mathrm{I}$ and $B a m \mathrm{HI}$ and ligated together with the 381 bp fragment of rhaA (XhoII-HindIII) into the vector pGEM-7Zf(-) (Promega), previously digested with Кри I and HindIII, generating plasmids pGAfrhaA and pGBfrhaA respectively. The rest of the ORF of rhaA (1819 bp) was obtained from pR22 through a double restriction $\mathrm{NcoI}-\mathrm{BamHI}$ and it was ligated to the $\operatorname{trpC}$ gene terminator sequence $\left(\operatorname{trp} C_{\mathrm{p}}\right)$, obtained from pAN7-1 (as a BamHI-SphI fragment of $773 \mathrm{bp}$ ), into the pUCMB20 vector (Roche) previously digested with NcoI-SphI, thus generating pUCfrhaAT.

Fragments $x \ln A_{\mathrm{p}}:: r h a A-381$ bp and $x \ln B_{\mathrm{p}}:: r h a A-381$ bp were isolated after a $K p n \mathrm{I}-\mathrm{NcoI}$ digestion and ligated to rhaA-1819pb::trp $C_{\mathrm{t}}$ (NcoI-SmaI) into the A. nidulans expression vector pILJ16 [46] previously digested with $K p n I$ and SmaI to generate the expression vectors pILArhaA and pILBrhaA (Additional file 1: Figure S1A and $B$ respectively).

\section{Construction of different $A$. nidulans strains expressing the rhaA gene of $A$. aculeatus}

A. nidulans AR4 (argB2, metG1, biA1) was used as the recipient for transformations with the $\arg B^{+}$-carrying plasmids pILArhaA and pILBrhaA (Additional file 1: Figure S1A and B), to generate AR137 and AR138 (relevant genotype $\left.x \ln A_{\mathrm{p}}:: r h a A\right)$ and AR142 and AR143 $\left(x \ln B_{\mathrm{p}}::\right.$ rha $\left.A\right)$, respectively. Transformant AR137 was crossed to AR83 (pabaA1, yA2, argB2, pac $C^{c} 14$ ) to obtain the strain AR152 (relevant genotype $x \ln A_{\mathrm{p}}:: r h a A, p a c C^{c} 14$ ), whereas transformant AR142 was crossed to AR181 (pabaA1, yA2, argB2, palA1) to isolate AR187 $\left(x \ln B_{\mathrm{p}}:: r h a A\right.$, palA1). Once $x \ln _{\mathrm{p}}:$ rhaA expressing strains with mutations in the $\mathrm{pH}$ regulatory circuit were isolated, AR152 and AR187 were subsequently crossed to AR66 (relevant genotype $g p d A_{\mathrm{p}}:: x \ln R$-argB2) [18]. Four descendants co-expressing $x \ln A_{\mathrm{p}}::$ rha $A$ and $x \ln B_{\mathrm{p}}::$ rhaA together with $g p d A_{\mathrm{p}}:: x \ln R$ were isolated: AR210 $\left(x \ln A_{\mathrm{p}}:: r h a A\right.$, $\left.\operatorname{gpd} A_{\mathrm{p}}:: x \ln R, \operatorname{argB2}, \operatorname{pabaA1}, \operatorname{biA1}\right), \mathrm{AR} 211\left(x \ln A_{\mathrm{p}}:: r h a A\right.$, $\left.\operatorname{gpd} A_{\mathrm{p}}:: x \ln R, \operatorname{argB2}, \operatorname{biA1}\right), \mathrm{AR} 201\left(x \ln B_{\mathrm{p}}:: r h a A, \operatorname{gpd} A_{\mathrm{p}}:: x \ln R\right.$, $\operatorname{argB2}, \operatorname{biA1})$ and AR206 $\left(x \ln B_{\mathrm{p}}:: \operatorname{rhaA}, g p d A_{\mathrm{p}}:: x \ln R\right.$, $\operatorname{argB2}$, metG1, biA1). In addition, two strains (AR207 and AR208) with the $x \ln B_{\mathrm{p}}:: r h a A$ cassette in $g p d A_{\mathrm{p}}:: x \ln R$, palA1 genetic backgrounds were also isolated. For yet unknown reasons, in repeated attempts, we were unable to obtain strains with the $x \ln A_{\mathrm{p}}:: r h a A$ expression cassette in $g p d A_{\mathrm{p}}:: x \ln R$; pac $C^{c} 14$ backgrounds.

$\alpha$-L-rhamnosidase production was tested in plate assays using MM-xylose plates supplemented with $40 \mu \mathrm{M}$ 4-methylumbelliferyl $\alpha$-L-rhamnopyranoside (MUR) and $1 \mathrm{mM}$ McIlvaine (citrate-phosphate) buffer $\mathrm{pH}$ 4.0. After incubation, hydrolysis of MUR was visualized under ultraviolet light. The $\operatorname{pac}^{c} 14$ mutation was identified by sequence analysis using oligonucleotides PacC923dir and PacC1650rev. palA1 mutations were confirmed by testing their inability to grow at alkaline $\mathrm{pH}$. The rapid DNA extraction procedure for PCR analysis developed in Aspergillus parasiticus [47] was applied to A. nidulans descendants to confirm the presence of the $\operatorname{gpd} A_{\mathrm{p}}:: x \ln R$ cassette (using oligonucleotides GpdAXho and XlnREco). All selected strains were also analyzed by Southern analysis to further confirm the presence of one copy of the $x \ln A_{\mathrm{p}}:: r h a A, x \ln B_{\mathrm{p}}:: r h a A$ and $g p d A_{\mathrm{p}}:: x \ln R$ cassettes integrated into the expected loci $(x \ln A$, chromosome II; $x \ln B$, chromosome VIII; and $\operatorname{argB}$, chromosome III, respectively). In this analyses, genomic DNAs from the untransformed (AR4), pILArhaA transformant and descendent strains were digested with $\mathrm{BamHI}$. After probing the blots with a DIG-labeled probe corresponding to 680 bp of the $x \ln A$ gene promoter, the AR137, AR138, AR152, AR210 and AR211 strains displayed 11,3 and a 3,9 kb bands corresponding to the insertion of the pILArhaA plasmid into $x \ln A$ whereas the untransformed (AR4) strain yielded a $6 \mathrm{~kb}$ band. A similar approach was used to analyze strains bearing the $x \ln B_{\mathrm{p}}:$ : rhaA cassette: their genomic DNAs were digested with $B g l \mathrm{II}$, and the Southern analyses showed 4.4 and $3 \mathrm{~kb}$ bands when the pILBrhaA plasmid was integrated into $x \ln B$ (strains AR142, AR143, AR187, AR201, AR206, AR207 and AR208, whereas the AR4 strain displayed a single $3.8 \mathrm{~kb}$ band. In this case, a $x \ln B_{\mathrm{p}} 645 \mathrm{bp}$ fragment was used as a probe. The correct integration of the $g p d A_{\mathrm{p}}:: x \ln R$ into $\operatorname{argB2}$ was also confirmed by Southern analysis in AR201, AR206, AR207, AR208, AR210 and AR211, using an $800 \mathrm{bp}$ fragment from the $\operatorname{argB}$ gene as a probe. The genomic DNA of the mentioned strains and that of the parental strain (AR66) were double digested with BamHI and EcoRI. All strains tested showed 7.7 and $3.8 \mathrm{~kb}$ bands and the descendants showed one additional band of $6.7 \mathrm{~kb}$ (AR210 and AR211) or 9.4 Kb (AR201, AR206, AR207 and AR208) corresponding to the $\operatorname{argB}$ selection marker within the pILArhaA and pILBrhaA plasmids.

\section{Enzyme activity assays}

Endo-1,4- $\beta$-xylanase (xylanase) activity was measured using azo-xylan from birchwood (Megazyme, Warriewood, Sydney, Australia) as a substrate. The reaction mixture contained $250 \mu \mathrm{l}$ of azo-xylan $\left(20 \mathrm{mg} \mathrm{ml}^{-1}\right)$ in $50 \mathrm{mM}$ succinic buffer pH 5.5 and $100 \mu$ of culture supernatant. After 10 minutes of incubation at $40^{\circ} \mathrm{C}$, the non-hydrolyzed xylan was precipitated with $1 \mathrm{ml}$ of ethanol $(96 \% \mathrm{v} / \mathrm{v})$ followed by a centrifugation step (3000 rpm during 10 minutes).

$\alpha$-L-rhamnosidase (rhamnosidase) activity was quantified using para-nitrophenyl $\alpha$-L-rhamnopyranoside ( $p$ NPR) as a substrate. The assay was performed in a final volume of 
$250 \mu \mathrm{l}$, in a reaction mixture containing $1.4 \mathrm{mM}$ of $p \mathrm{NPR}$ in $250 \mathrm{mM}$ Mcllvaine buffer $\mathrm{pH} 5.0$ for 15 minutes at $50^{\circ} \mathrm{C}$. Release of $p$-nitrophenol was measured spectrophotometrically at $400 \mathrm{~nm}$. One unit of enzyme activity was defined as the amount of enzyme that releases $1 \mathrm{mmol}$ of $p$-nitrophenol per minute in the same conditions. MMxylose plates supplemented with $40 \mu \mathrm{M}$ 4-methylumbelliferyl $\alpha$-L-rhamnopyranoside (MUR) were used for plate assays of $\alpha$-L-rhamnosidase activities. After incubation, hydrolysis of MUR was assessed under ultraviolet light.

Protein concentrations were determined using the Bradford assay and bovine serum albumin (BSA; Roche) as standard.

\section{Additional file}

Additional file 1: Figure S1. Construction and gene replacement analyses of the $x / n_{\mathrm{p}}::$ h $h a \mathrm{~A}$ strains. (A and $\mathbf{B}$ ) Maps of the vectors plLArhaA and pILBrhaA used to generate the $x \ln A_{p}: . r h a A(A R 137, A R 138)$ and $x \ln B_{p}:$. rhaA (AR142 and AR143) strains, respectively. Schematic diagrams of the $x \ln A$ and $x \ln B$ loci and gene replacement events are shown. ( $C$ and $\mathbf{D}$ ) Southern analyses of gene targeting events. Genomic DNAs from transformants were digested with BamHI (plLArhaA) or Bg/ll (plLBrhaA), electrophoresed, blotted and hybridized with specific probe fragments of $x \ln A_{p}(\mathbf{C})$ or $x \ln B_{p}(\mathbf{D})$. As a control, genomic DNA from the untransformed AR4 strain, digested with the same enzymes, was included. The sizes of the fragments are presented on the right of each blot.

\section{Abbreviations \\ BSA: Bovine serum albumin; CCR: Carbon catabolite repression; \\ CM: Complete medium; GH: Glycosyl hydrolase; MM: Minimal medium; MUR: 4-methylumbelliferyl a-L-rhamnopyranoside; ORF: Open reading frame; OSX: Oat spelt xylan; PCR: Polymerase chain reaction; $p$ NPR: $p$-nitrophenyl a-L-rhamnopyranoside; SD: standard deviation; XInR/Xyr 1: Xylan regulator.}

\section{Competing interests}

The authors declare that they have no competing interests.

\section{Authors' contributions}

JAT performed the experiments, analyzed the data and drafted the manuscript. MO conceived the study, designed and supervised the experiments, analyzed the data and wrote the manuscript. Both authors read and approved the final manuscript.

\section{Acknowledgements}

We wish to thank Adela Villanueva, Elsy Tamayo and Rómulo Luque for preliminary experiments on xylanase production, Andrew MacCabe for critical revision of the manuscript prior to submission, Miguel Angel Peñalva and Eduardo Espeso for strains, and the Sequencing Core Facility of the University of Valencia (Spain) for sequencing.

This work was supported by the Spanish Ministerio de Ciencia e Innovación/ FEDER (grant numbers AGL2002-01906, AGL2011-29925, given to MO, and CSD2007-0063/Consolider-Ingenio]. JAT was the recipient of a pre-doctoral fellowship (FPI, Formación de Personal de Investigador) from the Comisión Interministerial de Ciencia y Tecnología given to MO. The group also participates in the EC COST Action FA0907_BIOFLAVOUR.

\section{Author details}

${ }^{1}$ Instituto de Agroquímica y Tecnología de Alimentos, Consejo Superior de Investigaciones Científicas (IATA-CSIC), Agustín Escardino 7, 46980 Paterna, Valencia, Spain. ${ }^{2}$ Present address: Microbial Systems Biology, Laboratory of Systems and Synthetic Biology, Wageningen University, Dreijenplein 10, $6703 \mathrm{HB}$, Wageningen, The Netherlands.
Received: 13 December 2013 Accepted: 23 June 2014

Published: 4 July 2014

\section{References}

1. Carroll A, Somerville C: Cellulosic biofuels. Annu Rev Plant Biol 2009, 60:165-182.

2. Pauly $M$, Keegstra K: Plant cell wall polymers as precursors for biofuels. Curr Opin Plant Biol 2010, 13:305-312.

3. Merino ST, Cherry J: Progress and challenges in enzyme development for biomass utilization. Adv Biochem Eng Biotechnol 2007, 108:95-120.

4. Sweeney MD, Xu F: Biomass converting enzymes as industrial biocatalysts for fuels and chemicals: recent developments. Catalysts 2012, 2:244-263.

5. Martinez D, Berka RM, Henrissat B, Saloheimo M, Arvas M, Baker SE, Chapman J, Chertkov O, Coutinho PM, Cullen D, Danchin EG, Grigoriev IV, Harris $P$, Jackson M, Kubicek CP, Han CS, Ho I, Larrondo LF, de Leon AL, Magnuson JK, Merino S, Misra M, Nelson B, Putnam N, Robbertse B, Salamov AA, Schmoll M, Terry A, Thayer N, Westerholm-Parvinen A, et al: Genome sequencing and analysis of the biomass-degrading fungus Trichoderma reesei (syn. Hypocrea jecorina). Nat Biotechnol 2008, 26:553-560.

6. King BC, Waxman KD, Nenni NV, Walker LP, Bergstrom GC, Gibson DM: Arsenal of plant cell wall degrading enzymes reflects host preference among plant pathogenic fungi. Biotechnol Biofuels 2011, 4:4.

7. Andersen MR, Giese M, de Vries RP, Nielsen J: Mapping the polysaccharide degradation potential of Aspergillus niger. BMC Genomics 2012, 13:313.

8. Couturier M, Navarro D, Olivé C, Chevret D, Favel A, Lesage-Meessen L, Henrissat B, Coutinho PM, Berrin JG: Post-genomic analyes of fungal lignocellulosic biomass degradation reveal the unexpected potential of the plant pathogen Ustilago maydis. BMC Genomics 2012, 13:57.

9. Saykhedkar S, Ray A, Ayoubi-Canaan P, Hartson SD, Prade R, Mort AJ: A time course analysis of the extracellular proteome of Aspergillus nidulans growing on sorghum stover. Biotechnol Biofuels 2012, 5:52.

10. Zhao Z, Liu H, Wang C, Xu JR: Comparative analysis of fungal genomes reveals different plant cell wall degrading capacity in fungi. BMC Genomics 2013, 14:274.

11. Znameroski EA, Glass NL: Using a model filamentous fungus to unravel mechanisms of lignocellulose deconstruction. Biotechnol Biofuels 2013, 5:6.

12. Punt PJ, van Biezen N, Conesa A, Albers A, Mangnus J, van den Hondel C: Filamentous fungi as cell factories for heterologous protein production. Trends Biotechnol 2002, 20:200-206.

13. Lubertozzi D, Keasling JD: Developing Aspergillus as a host for heterologous expression. Biotechnol Adv 2009, 27:53-75.

14. Meyer V, Wu B, Ram AF: Aspergillus as a multi-purpose cell factory: current status and perspectives. Biotechnol Lett 2011, 33:469-476.

15. Coutinho PM, Andersen MR, Kolenova K, van Kuyk PA, Benoit I, Gruben BS,

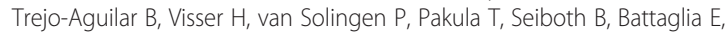
Aguilar-Osorio G, de Jong JF, Ohm RA, Aguilar M, Henrissat B, Nielsen J, Stålbrand H, de Vries RP: Post-genomic insights into the plant polysaccharide degradation potential of Aspergillus nidulans and comparison to Aspergillus niger and Aspergillus oryzae. Fungal Genet Biol 2009, 46:S161-S169.

16. Bauer S, Vasu P, Persson S, Mort AJ, Somerville CR: Development of a suite of polysaccharide-degrading enzymes for analyzing plant cell walls. Proc Natl Acad Sci U S A 2006, 103:11417-11422.

17. Stricker $A R$, Mach RL, de Graaff LH: Regulation of transcription of cellulases and hemicellulases-encoding genes in Aspergillus niger and Hypocrea jecorina (Trichoderma reesei). Appl Microbiol Biotechnol 2008, 78:211-220.

18. Tamayo EN, Villanueva A, Hasper AA, de Graaff LH, Ramón D, Orejas M: CreA mediates repression of the regulatory gene $x \ln R$ which controls the production of xylanolytic enzymes in Aspergillus nidulans. Fungal Genet Biol 2008, 45:984-993.

19. de Souza CP, Hashmi SB, Osmani AH, Andrews P, Ringelberg CS, Dunlap JC, Osmani SA: Functional analysis of the Aspergillus nidulans kinome. PLOS ONE 2012, 8:e58008.

20. Brown NA, de Gouvea FP, Krohn NG, Savoldo M, Goldman GH: Functional characterization of the non-essential protein kinases and phosphatases regulating Aspergillus nidulans hydrolytic enzyme production. Biotechnol Biofuel 2013, 6:91.

21. Blumenthal CZ: Production of toxic metabolites in Aspergillus niger, Aspergillus oryzae, and Trichoderma reesei: justification of mycotoxin testing in food grade enzyme preparations derived from the three fungi. Regul Toxicol Pharmacol 2004, 39:214-228. 
22. Frisvad C, Larsen TO, Thrane U, Meijer M, Varga J, Samson RA, Nielsen KF: Fumosin and ochratoxin production in industrial Aspergillus niger strains. PLOS ONE 2011, 6:e23496.

23. Caddick MX, Greenland AJ, Jepson I, Krause KP, Qu N, Riddell KV, Salter MG Schuch W, Sonnewald U, Tomsett AB: An ethanol inducible gene switch for plants used to manipulate carbon metabolism. Nat Biotechnol 1998, 16:177-180

24. Weber W, Rimann M, Spielmann M, Keller B, Daoud-El Baba M, Aubel D, Weber CC, Fussenegger M: Gas-inducible transgene expression in mammalian cells and mice. Nat Biotechnol 2004, 22:1440-1444.

25. MacCabe AP, Orejas M, Pérez-González JA, Ramón D: Opposite patterns of expression of two Aspergillus nidulans xylanase genes with respect to ambient pH. J Bacteriol 1998, 180:1331-1333.

26. Orejas M, MacCabe AP, Pérez González JA, Kumar S, Ramón D: Carbon catabolite repression of the Aspergillus nidulans xInA gene. Mol Microbiol 1999, 31:177-184.

27. Orejas M, MacCabe AP, Pérez-González JA, Kumar S, Ramón D: The wide-domain carbon catabolite repressor $\mathrm{CreA}$ indirectly controls expression of the Aspergillus nidulans $x \ln B$ gene, encoding the acidic endo-beta-(1,4)-xylanase X(24). J Bacterio/ 2001, 183:1517-1523.

28. Forment JV, Ramón D, MacCabe AP: Consecutive gene deletions in Aspergillus nidulans: application of the Cre/loxP system. Curr Genet 2006, 50:217-224.

29. Piñaga F, Fernández-Espinar MT, Vallés S, Ramón D: Xylanase production in Aspergillus nidulans. Induction and carbon catabolite repression. FEMS Microbiol Lett 1994, 115:319-323.

30. Prathumpai W, Mclntyre M, Nielsen J: The effect of CreA in glucose and xylose catabolism in Aspergillus nidulans. Appl Microbiol Biotechnol 2004, 63:748-753.

31. van Maris AJ, Abbott DA, Bellissimi E, van den Brink J, Kuyper M, Luttik MA Wisselink HW, Scheffers WA, van Dijken JP, Pronk JT: Alcoholic fermentation of carbon sources in biomass hydrolysates by Saccharomyces cerevisiae: current status. Antonie Van Leeuwenhoek 2006, 90:391-418.

32. Manzanares $P$, Vallés $S$, Ramón D, Orejas M: $\mathbf{a}$-L-Rhamnosidases: old and new insights. In Industrial enzymes, structure, function and applications. Edited by Polaina J, MacCabe AP. Dordrecht: Springer; 2007:117-140.

33. Juturu $\mathrm{V}, \mathrm{Wu} J \mathrm{~J}$ : Microbial xylanases: engineering, production and industrial applications. Biotechnol Adv 2012, 30:1219-1227.

34. Cohen BL: Regulation of intracellular and extracellular neutral and alkaline proteases in Aspergillus nidulans. J Gen Microbiol 1973 79:311-320

35. Serebrianyi VA, Sinitsyna OA, Fedorova EA, Okunev ON, Bekkarevich AO, Sokolova LM, Vinetskii lu P, Sinitsyn AP: Synthesis of xylanolytic enzymes and other carbohydrases by the fungus Penicillium canescens: transformants with an altered copy number of the gene $x \ln R$ and an encoding transcriptional activator. App/ Biochem Microbiol 2006, 42:584-591.

36. Mach-Aigner AR, Pucher ME, Steiger MG, Bauer GE, Preis SJ, Mach RL: Transcriptional regulation of $x y r 1$, encoding the main regulator of the xylanolytic and cellulolytic enzyme system in Hypocrea jecorina. Appl Environ Microbiol 2008, 74:6554-6562.

37. Manzanares P, Orejas M, Gil JV, de Graaff LH, Visser J, Ramón D: Construction of a genetically modified wine yeast strain expressing the Aspergillus aculeatus rhaA gene, encoding an alpha-L-rhamnosidase of enological interest. Appl Environ Microbiol 2003, 69:7558-7562.

38. Orejas M, Ibáñez E, Ramón D: The filamentous fungus Aspergillus nidulans produces an alpha-L-rhamnosidase of potential oenological interest. Lett Appl Microbiol 1999, 28:383-388.

39. Manzanares $P$, de Graaff $L H$, Visser J: Purification and characterization of an alpha-L-rhamnosidase from Aspergillus niger. FEMS Microbiol Lett 1997, 157:279-283.

40. Mutter M, Beldman G, Schols HA, Voragen AGJ: Rhamnogalacturonan alpha-L-rhamnopyranohydrolase. A novel enzyme specific for the terminal non reducing rhamnosyl unit in rhamnogalacturonan regions of pectin. Plant Physiol 1994, 106:241-250.

41. Pontecorvo G, Roper JA, Hemmons LM, Macdonald KD, Bufton AWJ: The genetics of Aspergillus nidulans. Adv Genet 1953, 5:141-238.

42. Cove DJ: Induction and repression of nitrate reductase in the fungus Aspergillus nidulans. Biochim Biophys Acta 1966, 113:51-56.

43. Sambrook J, Russell DW: Molecular cloning: a laboratory manual. Cold Spring Harbor, New York: Cold Spring Harbor Laboratory Press; 2001.
44. Tilburn J, Scazzocchio C, Taylor GG, Zabicky-Zissman JH, Lockington RA, Davies RW: Transformation by integration in Aspergillus nidulans. Gene 1983, 26:205-221.

45. Pérez-González JA, de Graaff LH, Visser J, Ramón D: Molecular cloning and expression in Saccharomyces cerevisiae of two Aspergillus nidulans xylanase genes. Appl Environ Microbiol 1996, 62:2179-2182.

46. Johnstone IL, Hughes SG, Clutterbuck AJ: Cloning an Aspergillus developmental gene by transformation. EMBO J 1985, 4:1307-1311.

47. Chiou CH, Miller M, Wilson DL, Trail F, Linz JE: Chromosomal location plays a role in regulation of aflatoxin gene expression in Aspergillus parasiticus. Appl Environ Microbiol 2002, 68:306-315.

doi:10.1186/1754-6834-7-103

Cite this article as: Tamayo-Ramos and Orejas: Enhanced glycosyl hydrolase production in Aspergillus nidulans using transcription factor engineering approaches. Biotechnology for Biofuels 2014 7:103.

\section{Submit your next manuscript to BioMed Central and take full advantage of:}

- Convenient online submission

- Thorough peer review

- No space constraints or color figure charges

- Immediate publication on acceptance

- Inclusion in PubMed, CAS, Scopus and Google Scholar

- Research which is freely available for redistribution

Submit your manuscript at www.biomedcentral.com/submit
C) Biomed Central 